\title{
Variabilidade e correlações entre caracteres agronômicos em caupi (Vigna unguiculata)(1)
}

Ângela Celis de Almeida Lopes ${ }^{(2)}$, Francisco Rodrigues Freire Filho(3), Ranyse Barbosa Querino da Silva ${ }^{(4)}$, Francilene Leonel Campos ${ }^{(5)}$ e Maurisrael de Moura Rocha ${ }^{(2)}$

Resumo - O caupi (Vigna unguiculata (L.) Walp) é um alimento básico das populações do Nordeste brasileiro, devendo merecer atenção com vistas a melhoria da qualidade de grãos, resistência a doenças e pragas e aumento de produtividade. Este trabalho teve por objetivo estudar a variabilidade e o potencial genético de 28 linhagens, escolhidas após uma seleção para cor, tamanho de grãos e resistência a viroses. A produtividade apresentou coeficiente de variação genético de $23,90 \%$, e o valor agronômico, de 3,56\%. O número de vagens por pedúnculo apresentou a menor estimativa do coeficiente de determinação genético $(4,51 \%)$, e o peso de 100 grãos, a maior $(81,74 \%)$. O coeficiente de determinação genético da produtividade foi de $34,15 \%$. As maiores estimativas de ganho genético foram as do peso de 100 grãos $(21,73 \%)$ e da produtividade $(19,77 \%)$. As correlações genotípicas foram superiores às fenotípicas e às de ambiente, destacando-se as correlações entre número de ramos secundários e produtividade $(68,13 \%)$, e valor agronômico e produtividade (100\%). Estes resultados mostram amplas possibilidades de seleção entre as linhagens com relação à maioria dos caracteres estudados.

Termos para indexação: progênie, seleção, variação genética, componentes de rendimento, produtividade.

\section{Genetic variability and correlations of agronomic characters in cowpea (Vigna unguiculata)}

\begin{abstract}
Cowpea (Vigna unguiculata (L.) Walp) is an important food crop for human population in northeastern Brazil. Studies aiming to increase its yield as well as to improve the grain quality and the insect and diseases resistance are needed. This work aimed to accomplish genetic studies in twentyeight cowpea advanced lines. The studied lines were chosen after selection for seed color and size and plant viruses resistance. The degree of genetic determination ranged from $4.51 \%$ (in pods/peduncle) to $81.74 \%$ (in 100 -seed weight). The seed yield degree of genetic determination was $34.15 \%$. The highest estimates of genetic gain were $21.73 \%$ to 100 -seed weight and $19.77 \%$ to seed yield. The genotypical correlations were higher than phenotypical and environmental ones. High correlations were found between fruiting branches/plant and seed yield (68.13\%) and between agronomic value and seed yield $(100 \%)$. This result indicates the selection feasibility for most of the studied traits.
\end{abstract}

Index terms: progeny, selection, genetic variation, yield components, productivity.

\footnotetext{
(1) Aceito para publicação em 28 de junho de 2000.

(2) ESALQ, Av. Pádua Dias, 11, Caixa Postal 83, CEP 13400-970 Piracicaba, SP. Bolsista do CNPq. E-mail: acalopes@carpa.ciagri.usp.br, mmrocha@carpa.ciagri.usp.br

(3) Embrapa-Centro de Pesquisa Agropecuária do Meio-Norte, Caixa Postal 01, CEP 64006-220 Teresina, PI. E-mail: freire@cpamn.embrapa.br

(4)ESALQ, Av. Pádua Dias, 11, Caixa Postal 83, CEP 13400-970 Piracicaba, SP. Bolsista da FAPESP. E-mail rbqsilva@carpa.ciagri.usp.br

${ }^{(5)}$ UNESP, Via de acesso Paulo Donato Castelanne, km 5 , CEP 14870-000 Jaboticabal, SP. Bolsista da FAPESP. E-mail flcampos@zipmail.com.br
}

\section{Introdução}

O caupi (Vigna unguiculata (L.) Walp) é um alimento básico das populações rural e urbana do Nordeste brasileiro. A FAO estima que 12,5 milhões de hectares são cultivados com caupi em todo o mundo, sendo 8 milhões de hectares apenas na África. Desse modo, é uma cultura que merece muita atenção, tendo em vista a melhoria de suas características agronômicas, principalmente as relacionadas ao rendimento. Para conseguir um aumento da produtividade é necessário entender melhor as correlações entre 
os componentes morfológicos de produtividade sem esquecer também os que se referem à qualidade dos grãos e à resistência a doenças e pragas. Alguns estudos têm sido realizados visando esclarecer a relação entre os componentes de produtividade em caupi (Kheradnam \& Niknejad, 1974; Lal et al., 1976; Zaveri et al., 1985; Oliveira et al., 1990; Umaharan et al., 1997), e existe um consenso quanto ao fato de que vários componentes, tais como número de grãos por vagem, comprimento de vagem e peso de 100 grãos, estão fortemente relacionados à produtividade de grãos. O conhecimento da associação da produtividade e de caracteres de rendimento é importante para seleção de parentais e populações segregantes. Desse modo, a informação das influências direta e indireta destas características ajuda a tornar a seleção mais efetiva (Bora et al., 1998).

Este trabalho teve como objetivo o estudo genético de um grupo de linhagens de caupi, identificando componentes de rendimento que estão relacionados a produção de grãos.

\section{Material e Métodos}

Utilizaram-se 28 linhagens e duas testemunhas que se destacaram após uma seleção quanto a cor, tamanho de grão e resistência a viroses, avaliadas mediante inoculação, nas plântulas, de um coquetel de vírus

O ensaio foi realizado em 1992, em condições de sequeiro, no campo experimental da Embrapa-Centro de Pesquisa Agropecuária do Meio-Norte em Teresina, PI, situado a uma altitude de $72 \mathrm{~m}$, latitude de $5^{\circ} 5^{\prime} 12^{\prime \prime} \mathrm{S}$ e longitude de 4248'42" W. O solo da área experimental é um Latossolo Vermelho-Amarelo de textura média (Melo Filho et al., 1980), representativo dos solos usados no cultivo de caupi no Estado do Piauí

O delineamento usado foi o de blocos ao acaso, com quatro repetições. Cada parcela foi constituída de três fileiras de 4,0 m, com espaçamento de 0,80 cm. Dentro da fileira, as covas foram feitas com espaços, entre si, de $0,25 \mathrm{~m}$, e foram semeadas quatro sementes por cova. Após 20 dias da semeadura, realizou-se o desbaste para uma planta por cova.

$\mathrm{Na}$ área útil da parcela, que correspondeu às duas fileiras centrais, foram etiquetadas, ao acaso, cinco plantas, nas quais foram coletados dados referentes aos seguintes caracteres: número de dias da germinação à antese da primeira flor (NDIF); número de nós no ramo principal no início da floração (NNRPIF); número de nós no ramo principal na maturidade (NNRPM); número de ramos secundários na maturidade (NRSM); comprimento do pedúnculo
(COMPP) $(\mathrm{cm})$; número de vagens por pedúnculo (NVP); comprimento da vagem $(\mathrm{COMPV})(\mathrm{cm})$; número de grãos por vagem (NGV) e peso de 100 grãos (P100G) (g). Considerando toda a área útil foram coletados os dados sobre valor agronômico, avaliado na maturidade, utilizando-se uma escala de um a cinco, em que um correspondeu a um material com pouco valor agronômico (pouco produtiva debulha prematura, suscetível a doenças), e cinco, a um material com excelentes características agronômicas (grande número de vagens, sem debulha das mesmas, vigor e sanidade) e a produtividade de grãos na área útil da parcela (PROD), transformada em quilogramas por hectare.

A análise de variância foi realizada segundo modelo fixo, fazendo-se o desdobramento do quadrado médio dos tratamentos. Em modelos fixos, foram estimados os componentes quadráticos, que expressam a variabilidade genética do material estudado. A partir da análise de variância, foram determinados o coeficiente de determinação genético (Falconer \& MacKay, 1996); o ganho genético esperado no grupo de genótipos estudado, com uma intensidade de seleção de $20 \%$, e coeficiente de variação genético Ainda, mediante a análise de variância realizou-se o cálculo das correlações fenotípicas, genotípicas e de ambiente entre os caracteres estudados. A significância dos coeficientes de correlação foi avaliada pela estatística t (Cruz \& Regazzi, 1994)

\section{Resultados e Discussão}

Entre as linhagens, na maioria dos caracteres constata-se uma ampla variabilidade, destacando-se as produtividades das linhagens TE $86-80-111 \mathrm{~F}$ e TE 87-115-13G, que alcançaram valores superiores a $1.800 \mathrm{~kg} / \mathrm{ha}$ (Tabela 1). Essa variabilidade pode ser confirmada pela significância do quadrado médio de tratamentos a $1 \%$ de probabilidade (Tabela 2).

Os coeficientes de determinação genético variaram muito de um caráter para outro, mas foram relativamente altos nos caracteres NDIF $(62,25 \%)$, NNRPFI (52,28\%), COMPV (75,66\%) e P100G (81,74\%), e intermediárias no NGV (34,14\%) e no PROD (34,15\%). Apesar de o caráter PROD também apresentar um valor intermediário de coeficiente de determinação genético, isso não deixa de ser importante, pois tal caráter, mais que outros, é muito influenciado pelos fatores ambientais. O caráter NVP, apesar de ser um importante componente de rendimento, é altamente instável, exibindo baixo valor $(4,51 \%)$ e possuindo limitada variabilidade genética, com 2-3 vagens por pedúnculo (Lush \& Evans, 
Tabela 1. Estimativas de médias de onze caracteres agronômicos em linhagens de caupi ${ }^{(1)}$.

\begin{tabular}{|c|c|c|c|c|c|c|c|c|c|c|c|}
\hline Tratamento & NDIF & NNRPIF & NNRPM & NRSM & $\begin{array}{c}\text { COMPP } \\
(\mathrm{cm})\end{array}$ & NVP & $\begin{array}{c}\text { COMPV } \\
(\mathrm{cm})\end{array}$ & NGV & P100G (g) & $\mathrm{VA}^{(2)}$ & $\begin{array}{l}\text { PROD } \\
\text { (kg/ha) }\end{array}$ \\
\hline TE 86-73-6G & 40,85 & 13,45 & 17,80 & 4,70 & 35,47 & 1,78 & 19,23 & 14,95 & 12,67 & 2,06 & 1425,13 \\
\hline TE $86-80-3 \mathrm{G}$ & 43,40 & 18,15 & 21,69 & 4,60 & 35,70 & 1,60 & 14,67 & 14,40 & 11,16 & 2,06 & 1464,28 \\
\hline TE $86-80-33 \mathrm{~F}$ & 39,45 & 14,35 & 17,80 & 4,95 & 36,30 & 1,85 & 15,65 & 14,90 & 11,45 & 2,12 & 1497,83 \\
\hline TE $86-80-36 \mathrm{~F}$ & 39,45 & 14,90 & 18,90 & 4,55 & 31,65 & 1,45 & 13,73 & 14,75 & 9,33 & 1,93 & 898,05 \\
\hline TE $86-80-56 \mathrm{~F}$ & 41,05 & 15,20 & 17,20 & 4,20 & 42,18 & 1,85 & 15,60 & 15,25 & 10,11 & 2,00 & 1296,88 \\
\hline TE $86-80-68 \mathrm{~F}$ & 43,40 & 15,30 & 18,70 & 4,35 & 37,20 & 1,40 & 15,70 & 14,60 & 11,04 & 2,00 & 949,53 \\
\hline TE $86-80-37 \mathrm{~F}$ & 45,80 & 17,60 & 21,65 & 5,00 & 34,97 & 1,70 & 16,55 & 16,13 & 10,78 & 1,99 & 1060,85 \\
\hline TE $86-80-75 \mathrm{~F}$ & 40,90 & 15,85 & 20,60 & 5,30 & 36,03 & 1,58 & 14,23 & 13,83 & 11,33 & 1,99 & 1005,30 \\
\hline TE $86-80-78 \mathrm{~F}$ & 40,50 & 13,45 & 18,65 & 4,15 & 32,65 & 2,00 & 14,98 & 13,95 & 10,41 & 1,87 & 682,75 \\
\hline TE $86-80-86 \mathrm{~F}$ & 38,90 & 13,05 & 15,20 & 4,00 & 33,38 & 1,70 & 17,30 & 15,00 & 11,34 & 1,93 & 1213,38 \\
\hline TE $86-80-92 \mathrm{~F}$ & 45,70 & 17,35 & 21,83 & 4,45 & 38,58 & 1,83 & 15,00 & 14,40 & 8,70 & 1,80 & 661,42 \\
\hline TE $86-80-92 \mathrm{~F}$ & 45,70 & 17,35 & 21,83 & 4,45 & 38,58 & 1,83 & 15,00 & 14,40 & 8,70 & 1,80 & 661,42 \\
\hline TE $86-80-102 \mathrm{~F}$ & 42,15 & 16,45 & 19,17 & 4,85 & 41,50 & 1,30 & 16,80 & 15,10 & 11,44 & 2,00 & 1249,43 \\
\hline TE $86-80-110 \mathrm{~F}$ & 42,25 & 16,30 & 19,45 & 4,85 & 37,43 & 1,80 & 14,60 & 14,15 & 10,63 & 2,00 & 874,15 \\
\hline TE $86-80-111 \mathrm{~F}$ & 40,85 & 15,70 & 17,00 & 4,75 & 35,05 & 1,65 & 16,45 & 15,25 & 11,46 & 2,06 & 1887,53 \\
\hline TE 87-96-4G & 40,90 & 12,53 & 15,90 & 4,07 & 37,50 & 1,78 & 17,67 & 15,65 & 13,08 & 1,87 & 1001,50 \\
\hline TE $87-115-2 \mathrm{G}$ & 40,15 & 12,65 & 16,95 & 4,23 & 31,35 & 1,83 & 17,73 & 14,33 & 15,54 & 1,80 & 1060,93 \\
\hline TE $87-115-3 \mathrm{G}$ & 43,55 & 15,05 & 18,68 & 4,05 & 31,65 & 1,63 & 19,98 & 15,43 & 15,80 & 1,93 & 857,00 \\
\hline TE $87-115-7 \mathrm{G}$ & 41,45 & 13,75 & 16,97 & 3,50 & 31,83 & 1,50 & 16,53 & 13,70 & 14,40 & 1,93 & 778,18 \\
\hline TE $87-115-11 \mathrm{G}$ & 42,75 & 15,25 & 17,25 & 4,33 & 31,63 & 1,43 & 15,95 & 14,28 & 16,17 & 1,87 & 841,63 \\
\hline TE $87-115-12 \mathrm{G}$ & 42,15 & 15,60 & 18,47 & 4,68 & 35,40 & 1,63 & 16,92 & 15,33 & 14,45 & 2,00 & 892,43 \\
\hline TE $87-115-13 \mathrm{G}$ & 42,30 & 13,80 & 17,73 & 4,20 & 31,43 & 1,50 & 17,38 & 13,95 & 13,61 & 1,87 & 1861,23 \\
\hline TE $87-124-11 \mathrm{G}$ & 41,05 & 15,25 & 18,65 & 4,50 & 38,98 & 1,47 & 18,30 & 16,87 & 15,88 & 2,06 & 1083,40 \\
\hline TE $87-133-11 \mathrm{G}$ & 40,45 & 13,50 & 19,28 & 4,48 & 35,63 & 1,60 & 19,50 & 16,90 & 14,48 & 1,93 & 817,73 \\
\hline TE $87-133-01 G$ & 41,20 & 14,55 & 18,70 & 4,20 & 37,55 & 1,50 & 19,60 & 16,25 & 15,46 & 2,00 & 1171,40 \\
\hline TE $87-133-15 G$ & 40,35 & 13,67 & 16,70 & 4,50 & 32,22 & 1,60 & 20,20 & 16,17 & 15,95 & 2,00 & 1326,75 \\
\hline TE $87-133-35 \mathrm{G}$ & 40,70 & 15,05 & 17,03 & 4,38 & 37,28 & 1,68 & 19,72 & 16,88 & 14,51 & 1,73 & 397,50 \\
\hline TE $87-133-23 \mathrm{G}$ & 40,05 & 13,75 & 17,25 & 4,60 & 37,32 & 1,45 & 20,00 & 15,98 & 14,99 & 1,93 & 932,95 \\
\hline TE $87-133-35 G$ & 40,70 & 15,05 & 17,03 & 4,38 & 37,28 & 1,68 & 19,72 & 16,88 & 14,51 & 1,73 & 397,50 \\
\hline TE $87-135-4 \mathrm{G}$ & 41,80 & 13,75 & 16,80 & 4,60 & 38,72 & 1,33 & 18,58 & 15,85 & 13,62 & 2,00 & 1189,43 \\
\hline CE-315 (Test.) & 46,35 & 19,05 & 20,35 & 5,05 & 39,00 & 1,93 & 17,63 & 17,00 & 10,29 & 2,00 & 1121,00 \\
\hline BR 14-Mulato (Test) & 44,15 & 15,60 & 19,03 & 5,15 & 38,88 & 1,38 & 17,70 & 15,85 & 13,94 & 2,00 & 620,55 \\
\hline $\begin{array}{l}\text { Média das } \\
\text { linhagens }\end{array}$ & 41,55 & 14,83 & 18,28 & 4,46 & 35,59 & 1,62 & 17,09 & 15,14 & 12,84 & 1,95 & 1049,21 \\
\hline $\begin{array}{l}\text { Média das } \\
\text { testemunhas }\end{array}$ & 45,25 & 17,32 & 19,68 & 5,10 & 38,93 & 1,65 & 17,66 & 16,42 & 12,11 & 2,00 & 870,77 \\
\hline $\mathrm{CV}(\%)$ & 2,91 & 8,42 & 11,64 & 12,32 & 11,28 & 19,84 & 6,24 & 7,14 & 8,11 & 5,92 & 33,56 \\
\hline
\end{tabular}

(1)NDIF: número de dias da germinação à antese da primeira flor; NNRPIF: número de nós no ramo principal no início da floração; NNRPM: número de nós no ramo principal na maturidade; NRSM: número de ramos secundários na maturidade; COMPP: comprimento de pedúnculo; NVP: número de vagens por pedúnculo; COMPV: comprimento de vagem; NGV: número de grãos por vagem; P100G: peso de 100 grãos; VA: valor agronômico; PROD: produtividade de grãos. ${ }^{(2)}$ Dados transformados em $\sqrt{\mathrm{x}+1}$.

Tabela 2. Estimativas de quadrados médios de tratamentos e resíduos de onze caracteres agronômicos em linhagens de caupi $^{(1)}$.

\begin{tabular}{lrrrrllllllll}
\hline $\begin{array}{l}\text { Fonte de } \\
\text { variação }\end{array}$ & GL & NDIF & NNRPIF & NNRPM & NRSM & COMPP & NVP & COMPV & NGV & P100G & VA ${ }^{(2)}$ & PROD \\
\hline Linhagens & 27 & $11,31^{* *}$ & $8,59^{* *}$ & $11,22^{* *}$ & $0,5393^{* *}$ & $37,41^{* *}$ & 0,1233 & $15,35^{* *}$ & $3,64^{* *}$ & $20,39^{* *}$ & $0,0328^{* *}$ & $372792,0^{* *}$ \\
Testemunha & 1 & $9,68^{* *}$ & $23,80^{* *}$ & 3,51 & 0,0199 & 0,32 & $0,6050^{* *}$ & 0,01 & 2,64 & $26,60^{*}$ & 0,0000 & $500900,0^{*}$ \\
Lin. vs. Test. & 1 & $102,02^{* *}$ & $46,46^{* *}$ & 14,70 & $3,0176^{* *}$ & $83,60^{*}$ & 0,0064 & 2,44 & $12,15^{* *}$ & 3,99 & 0,0160 & 237740,0 \\
Resíduo & 87 & 1,48 & 1,59 & 4,57 & 0,3084 & 16,33 & 0,1037 & 1,14 & 1,18 & 1,07 & 0,0134 & 121247,6 \\
\hline
\end{tabular}

(1)NDIF: número de dias da germinacão à antese da primeira flor; NNRPIF: número de nós no ramo principal no início da floração; NNRPM: número de nós no ramo principal na maturidade; NRSM: número de ramos secundários na maturidade; COMPP: comprimento de pedúnculo; NVP: número de vagens por pedúnculo; COMPV: comprimento de vagem; NGV: número de grãos por vagem; P100G: peso de 100 grãos; VA: valor agronômico; PROD: produtividade de grãos. ${ }^{(2)}$ Dados transformados em $\sqrt{\mathrm{x}+1}$. 
1981). Bapna et al. (1972), Aryeetey \& Laing (1973) e Fernandez \& Miller Junior (1985) também observaram baixa herdabilidade para NVP, chegando a afirmar que o número de vagens é um dos componentes de rendimento mais afetados pelas mudanças ambientais.

O coeficiente de variação genético da maioria dos caracteres foi superior a 5\%; merecem destaque os caracteres COMPV (11,03\%), P100G (17,10\%) e PROD (23,90\%) (Tabela 3$)$. Tais valores indicam a existência de variabilidade genética de diferentes caracteres, entre os genótipos de caupi, possibilitando a realização de seleção. Bora et al. (1998) também calcularam o CVG dos caracteres peso de 100 grãos (17,04\%) e produtividade $(33,07 \%)$ em Vicia faba.

Neste estudo, o ganho genético esperado, na maioria dos caracteres, foi inferior a 5\%, denotando, assim, que nestes caracteres os ganhos com seleção serão lentos. No entanto, em caracteres importantes como COMPV, P100G e PROD, foram, respectivamente, de 13,40, 21,73 e 19,77\%, evidenciando que neste grupo de linhagens, através da seleção, podese obter uma considerável melhoria na expressão destes caracteres. Os caracteres COMPV e P100G apresentaram alto coeficiente de determinação genético combinado com razoável ganho genético, possibilitando um aumento da produtividade através da seleção direta destes caracteres.

Em sua maioria, as correlações genotípicas foram superiores às fenotípicas, e estas, superiores às de ambiente (Tabela 4). O NDIF apresentou correlação genotípica e fenotípica positiva e significativa com NNRPFI e NNRPM. O NNRPIF apresentou correlações fenotípicas e genotípicas positivas e signifi- cativas com NNRPM e NRSM, e negativas significativas com COMPV e P100G. O NNRPM apresentou correlações fenotípicas e genotípicas positivas e significativas com NRSM, e negativas e significativas com COMPV e P100G. Estes resultados confirmam os observados no NNRPIF, e mostram que a seleção para aumento no número de nós no ramo principal implica a redução do COMPV e do P100G. A alta correlação entre NNRPIF e NNRPM indica que estes caracteres representam a mesma medida, só que em estágios diferentes, podendo-se utilizar apenas uma das medidas para efeito de estudo. O NRSM apresentou correlação genotípica positiva e significativa, com COMPP e PROD e negativa com P100G. A correlação entre NRSM e PROD é um dado importante, pois foi a única que influenciou a produtividade, e merece mais atenção no melhoramento do caupi.

O COMPP, que é um caráter pouco estudado em caupi, apresentou correlações genotípicas positivas e significativas com NGV e VA, e negativas e significativas com NVP e P100G, que são componentes de produtividade.

O NVP apresentou correlação genotípica negativa e significativa com COMPV, NGV, P100G e VA, o que concorda com Ismail \& Hall (1998), que obtiveram correlação genotípica de $-0,83$ com NVP e NGV. As correlações negativas constituem grande dificuldade para o melhorista, porque a melhoria de determinado caráter freqüentemente implica a redução do outro, e todos são importantes componentes de produtividade. Muitos autores sugerem que o aumento no NVP pode ser um dos objetivos para aumentar a produtividade (Jindla \& Gupta, 1984; Kahn \& Stoffella, 1985). Isto foi reforçado por

Tabela 3. Estimativas do coeficiente de variação genético, coeficiente de determinação genético e ganho genético esperado de onze caracteres agronômicos em linhagens de caupi ${ }^{(1)}$.

\begin{tabular}{|c|c|c|c|c|c|c|c|c|c|c|c|}
\hline Parâmetros & NDIF & NNRPIF & NNRPM & NRSM & COMPP & NVP & COMPV & NGV & P100G & $\mathrm{VA}^{(2)}$ & PROD \\
\hline $\begin{array}{l}\text { Coeficiente de } \\
\text { determinação genético (\%) }\end{array}$ & 62,25 & 52,28 & 26,62 & 15,76 & 24,11 & 4,51 & & 34,14 & 81,74 & 26,57 & 34,15 \\
\hline $\begin{array}{l}\text { CV genético }(\%) \\
\text { Ganho genético esperado }\end{array}$ & 3,77 & 8,92 & 7,05 & 5,38 & 6,40 & 4,32 & 11,03 & 5,17 & 17,10 & 3,56 & 23,90 \\
\hline na amostra & 4,14 & 8,93 & 5,06 & 2,96 & 4,37 & 1,28 & 13,40 & 4,20 & 21,73 & 2,57 & 19,77 \\
\hline
\end{tabular}

(1)NDIF: número de dias da germinação à antese da primeira flor; NNRPIF: número de nós no ramo principal no início da floração; NNRPM: número de nós no ramo principal na maturidade; NRSM: número de ramos secundários na maturidade; COMPP: comprimento de pedúnculo; NVP: número de vagens por pedúnculo; COMPV: comprimento de vagem; NGV: número de grãos por vagem; P100G: peso de 100 grãos; VA: valor agronômico; PROD: produtividade de grãos. ${ }^{(2)}$ Dados transformados em $\sqrt{\mathrm{x}+1}$ 
Tabela 4. Estimativas de correlações fenotípicas (CF), genotípicas (CG) e de ambiente (CE) entre onze caracteres agronômicos em linhagens de caupi ${ }^{(1)}$

\begin{tabular}{|c|c|c|c|c|c|c|c|c|c|c|c|}
\hline Caráter & Correlação & NNRPIF & NNRPM & NRSM & $\begin{array}{c}\text { COMPP } \\
(\mathrm{cm})\end{array}$ & NVP & $\begin{array}{c}\text { COMPV } \\
(\mathrm{cm})\end{array}$ & NGV & P100G (g) & $\mathrm{VA}^{(2)}$ & $\begin{array}{l}\text { PROD } \\
(\mathrm{kg} / \mathrm{ha})\end{array}$ \\
\hline \multirow[t]{3}{*}{ NDIF } & $\mathrm{CF}$ & $0,7054 * *$ & $0,6660 * *$ & 0,1128 & 0,1296 & $-0,0833$ & $-0,1954$ & $-0,1249$ & $-0,1909$ & $-0,0634$ & $-0,0200$ \\
\hline & CG & $0,7465^{* *}$ & $0,8563 * *$ & 0,2510 & 0,3621 & $-0,1720$ & $-0,2198$ & $-0,1792$ & $-0,1968$ & $-0,1021$ & $-0,2637$ \\
\hline & $\mathrm{CA}$ & $0,5212 * *$ & 0,2225 & $-0,1447$ & $-0,0469$ & $-0,0723$ & 0,0180 & 0,0689 & $-0,1615$ & 0,0382 & 0,0158 \\
\hline \multirow[t]{3}{*}{ NNRPIF } & $\mathrm{CF}$ & & $0,7963^{* *}$ & $0,4965^{* *}$ & 0,3277 & $-0,1028$ & $-0,4780 * *$ & $-0,0933$ & 0,4629 & 0,2458 & 0,0691 \\
\hline & $\mathrm{CG}$ & & $1,0343^{* *}$ & 0,7879 ** & $0,4459^{*}$ & $-0,2382$ & $-0,5528 * *$ & $-0,1595$ & $-0,5010 * *$ & 0,3632 & 0,1280 \\
\hline & $\mathrm{CA}$ & & 0,2896 & 0,01206 & 0,0958 & $-0,0395$ & 0,0457 & 0,1254 & $-0,1594$ & $-0,0223$ & $-0,1944$ \\
\hline \multirow[t]{3}{*}{ NNRPM } & $\mathrm{CF}$ & & & $0,4903 * *$ & 0,1763 & 0,2597 & $-0,4303 *$ & $-0,1394$ & $0,4263^{*}$ & 0,1498 & $-0,1264$ \\
\hline & $\mathrm{CG}$ & & & 0,8463 ** & 0,3451 & $-0,0742$ & $-0,6343 * *$ & $-0,3371$ & $-0,5351 * *$ & 0,1511 & $-0,1725$ \\
\hline & $\mathrm{CA}$ & & & 0,1588 & $-0,0474$ & 0,8238 & 0,2242 & 0,1995 & $-0,1846$ & 0,1500 & $-0,0323$ \\
\hline \multirow[t]{3}{*}{ NRSM } & $\mathrm{CF}$ & & & & 0,3308 & $-0,0475$ & $-0,2418$ & 0,0921 & $-0,3109$ & $-0,1381$ & 0,3319 \\
\hline & $\mathrm{CG}$ & & & & $0,5471 * *$ & 0,0134 & $-0,3477$ & 0,1698 & $-0,4677^{*}$ & $-0,1971$ & $0,6813 * *$ \\
\hline & $\mathrm{CA}$ & & & & 0,1286 & $-0,0789$ & $-0,1311$ & $-0,0322$ & $-0,0757$ & 0,0697 & $-0,1524$ \\
\hline \multirow[t]{3}{*}{ СOMPP } & $\mathrm{CF}$ & & & & & $-0,0709$ & $-0,0144$ & 0,3529 & $-0,2817$ & 0,2817 & 0,1667 \\
\hline & $\mathrm{CG}$ & & & & & $-0,5510^{* *}$ & $-0,0036$ & $0,6637 * *$ & $-0,3975^{*}$ & $0,4790 * *$ & 0,2450 \\
\hline & $\mathrm{CA}$ & & & & & 0,1765 & $-0,0551$ & $-0,1365$ & 0,0593 & 0,0141 & 0,0328 \\
\hline \multirow[t]{3}{*}{ NVP } & $\mathrm{CF}$ & & & & & & $-0,1939$ & $-0,1750$ & $-0,3357$ & $-0,1697$ & $-0,0037$ \\
\hline & $\mathrm{CG}$ & & & & & & $-0,7127 * *$ & $-0,9855^{* *}$ & $-0,9076^{* *}$ & $-0,7776^{* *}$ & $-0,0561$ \\
\hline & $\mathrm{CA}$ & & & & & & 0,3104 & 0,2748 & 0,0555 & 0,1230 & 0,0243 \\
\hline \multirow[t]{3}{*}{ COMPV } & $\mathrm{CF}$ & & & & & & & $0,7072^{* *}$ & $0,7630 * *$ & $-0,1070$ & $-0,0243$ \\
\hline & CG & & & & & & & $0,8001^{* *}$ & $0,8136^{* *}$ & $-0,1738$ & $-0,0369$ \\
\hline & $\mathrm{CA}$ & & & & & & & $0,4750^{* *}$ & 0,0105 & 0,1260 & 0,0461 \\
\hline \multirow[t]{3}{*}{ NGV } & $\mathrm{CF}$ & & & & & & & & $0,4185^{*}$ & 0,8826 & 0,0395 \\
\hline & CG & & & & & & & & $0,5299 * *$ & 0,0878 & 0,0362 \\
\hline & $\mathrm{CA}$ & & & & & & & & $-0,0491$ & 0,0777 & 0,0627 \\
\hline \multirow[t]{3}{*}{ P100G } & $\mathrm{CF}$ & & & & & & & & & $-0,1381$ & $-0,1332$ \\
\hline & $\mathrm{CG}$ & & & & & & & & & $-0,1971$ & $-0,2065$ \\
\hline & $\mathrm{CA}$ & & & & & & & & & 0,0697 & 0,2342 \\
\hline \multirow[t]{3}{*}{ VA } & $\mathrm{CF}$ & & & & & & & & & & $0,7573 * *$ \\
\hline & $\mathrm{CG}$ & & & & & & & & & & $1,0731 * *$ \\
\hline & $\mathrm{CA}$ & & & & & & & & & & 0,2308 \\
\hline
\end{tabular}

(1)NDIF: número de dias da germinação à antese da primeira flor; NNRPIF: número de nós no ramo principal no início da floração; NNRPM: número de nós no ramo principal na maturidade; NRSM: número de ramos secundários na maturidade; COMPP: comprimento de pedúnculo; NVP: número de vagens por pedúnculo; COMPV: comprimento de vagem; NGV: número de grãos por vagem; P100G: peso de 100 grãos; VA: valor agronômico; PROD: produtividade de grãos. (2)Dados transformados em $\sqrt{\mathrm{x}+1} \cdot *$ e $*$ Significativo a $5 \%$ e $1 \%$ de probabilidade, respectivamente.

Summerfield et al. (1985), citados por Umaharan et al. (1997), que concluíram, a partir de estudos fisiológicos em caupi, que o número de nós reprodutivos é provavelmente mais importante que a eficiência reprodutiva como explicação para variações na produtividade, embora o coeficiente de determinação genético do caráter varie de moderado a baixo. No entanto, Fernandez \& Miller Junior (1985) afirmaram que, para aumentar a produtividade em caupi, pelo menos um dos componentes de produtividade deve ser considerado, e que, embora o número de vagens seja importante, ele é instável, com baixa herdabilidade, e é influenciado por fatores morfológicos e fisiológicos de crescimento e desenvolvimento da planta. Dessa forma, para aumentar o caráter vagens por planta, deve-se modificar a arquitetura do caupi, para que mais vagens sejam formadas e mantidas até a maturidade (Adams, 1982).
O COMPV apresentou correlações fenotípicas e genotípicas positivas e significativas com NGV e P100G; isto é bastante lógico, uma vez que com o aumento da vagem deve ocorrer também o aumento do NGV e P100G. Esses resultados confirmam os obtidos por Aryeetey \& Laing (1973) e Jindla \& Gupta (1984).

O NGV apresentou correlação fenotípica e genotípica positiva e significativa com P100G. Este fato discorda dos relatos de Aryeetey \& Laing (1973) e Kheradnam \& Niknejad (1974), que obtiveram correlações genotípicas negativas e significativas de $-0,98$ e $-0,41$, respectivamente.

O VA apresentou correlação fenotípica e genotípica positiva e significativa com PROD. Graças ao valor elevado desta correlação, é possível sugerir que, para o conjunto de genótipos avaliados, a seleção para VA pode ser tão eficiente quanto a sele- 
ção direta para incrementar a produtividade. Este é um resultado muito importante, porque mediante a seleção visual, o VA pode representar aumento de eficiência na seleção de melhores genótipos, principalmente nas avaliações iniciais de produtividade, quando, geralmente, se tem grande número de genótipos. A utilização do VA contribuirá para reduzir o tempo e os recursos despendidos na fase inicial de avaliação.

\section{Conclusões}

1. A população das linhagens reúne uma razoável variabilidade genética, notadamente na produtividade.

2. As correlações entre produtividade e seus componentes mais importantes são altas e significativas.

3. Destaca-se a correlação entre produtividade e número de ramos secundários na produtividade, que pode indicar que, para esta população, a produtividade pode ser melhorada mediante a seleção para um aumento no número de ramos secundários na produtividade.

4. Pela alta correlação entre produtividade e valor agronômico, pode-se sugerir que a seleção para valor agronômico pode ser tão eficiente quanto a seleção direta, para incrementar a produtividade.

\section{Referências}

ADAMS, M. W. Plant architecture and yield breeding Iowa State Journal of Research, Ames, v. 56, n. 3, p. 225254,1982

ARYEETEY, A. N.; LAING, E. Inheritance of yield components and their correlation with yield in cowpea (Vigna unguiculata L. Walp). Euphytica, Dordrecht, v. 22, p. 386-392, 1973

BAPNA, C. S.; JOSHI, S. N.; KABRIA, M. M. Correlation studies on yield and agronomic characters in cowpea (Vigna unguiculata L. Walp). Indian Journal of Agronomy, New Delhi, v. 17, p. 321-324, 1972.

BORA, G. C.; GUPTA, S. N.; TOMER, Y. S.; SINGH, S. Genetic variability, correlation and path analysis in faba bean (Vicia faba). Indian Journal of Agricultural Sciences, New Delhi, v. 68, n. 4, p. 212-214, 1998.

CRUZ, C. D.; REGAZZI,A. J. Modelos biométricos aplicados ao melhoramento genético. Viçosa : UFV-Imprensa Universitária, 1994. 390 p
FALCONER, D.S; MACKAY, T. F. C. Variance. In: FALCONER, D. S.; MacKAY, T. F. C. (Ed.). Introduction to quantitative genetics. Essex : Longman Scientific and Technical, 1996. p. 122-143.

FERNANDEZ, G. C. J.; MILLER JUNIOR, J. C. Yield component analysis in five cowpea cultivars. American Society for Horticultural Science Journal, Alexandria, v. 110, n. 4 , p. $553-559,1985$.

ISMAIL, A. M.; HALL, A. E. Positive and potential negative effects of heat-tolerance genes in cowpea. Crop Science, Madison, v. 38, n. 2, p. 381-390, 1998

JINDLA, S. K.; GUPTA, B. S. Component analysis of yield in cowpea. Indian Journal of Agricultural Sciences, New Delhi, v. 54, n. 3, p. 183-185, 1984.

KAHN, B. A.; STOFFELLA, P. J. Yield components of cowpea in two environments. Crop Science, Madison, v. 25, n. 1, p. $179-182,1985$

KHERADNAM, M.; NIKNEJAD, M. Heritability estimates and correlation of agronomic characters in cowpea (Vigna unguiculata L. Walp). Journal of Agricultural Science, Cambridge, Grã-Bretanha, v. 82, p. 207-208, 1974.

LAL, S. M.; SINGH, M.; PARTHAK, M. M. Combining ability of cowpea. Indian Journal of Genetics and Plant Breeding, Calcutta, v. 35, p. 375-378, 1976

LUSH, W. M.; EVANS, L. T. Domestication and improvement of cowpea. Euphytica, Dordrecht, v. 30, p. $579-587,1981$

MELO FILHO, H. F. R.; MEDEIROS, L. A. R.; JACOMINE, P. K. T. Levantamento detalhado dos solos da área da UEPAE de Teresina, PI. Rio de Janeiro Embrapa-SNLCS, 1980. 154 p. (Embrapa-SNLCS. Boletim Técnico, 69)

OLIVEIRA, F. J. de; VAREJÃO-SILVA, M. A.; GOMES, M. J. Seleção de caracteres agronômicos do caupi usando coeficiente de caminhamento. Pesquisa Agropecuária Brasileira, Brasília, v. 25, n. 7, p. 1055-1064, jul. 1990.

UMAHARAN, P.; ARIYANAGAM, R. P.; HAQUE, S. Q Genetic analysis of yield and its components in vegetable cowpea (Vigna unguiculata L. Walp). Euphytica, Dordrecht, v. 96, n. 2, p. 207-213, 1997.

ZAVERI, P. P.; PATEL, P. K.; YADAVENDRA, J. P.; SHAH, R. M. Heterosis and combining ability in cowpea. Indian Journal of Agricultural Sciences, New Delhi, v. 43, p. $807-810,1985$ 